Check for updates

Cite this: RSC Adv., 2018, 8, 775

Received 23rd November 2017 Accepted 18th December 2017

DOI: $10.1039 / c 7 r a 12715 d$

rsc.li/rsc-advances

\section{A new strategy for the sensitive electrochemical determination of nitrophenol isomers using $\beta$-cyclodextrin derivative-functionalized silicon carbide $\uparrow$}

\begin{abstract}
Shilian Wu, ${ }^{a}$ Shuangmei Fan, ${ }^{a}$ Shuang Tan, ${ }^{a}$ Jiaqiang Wang ${ }^{b}$ and Can-Peng Li (D) *a
In the present study, thiol $\beta$-cyclodextrin ( $\mathrm{SH}-\mathrm{CD})$ and ethylenediamine $\beta$-cyclodextrin $\left(\mathrm{NH}_{2}-\beta-\mathrm{CD}\right)$ were simultaneously grafted on the same interface of an Au NP deposited carboxyl SiC (AuaCSiC) nanocomposite. An electrochemical sensor for the simultaneous determination of nitrophenol isomers (Onitrophenol, o-NP; $p$-nitrophenol, $p$-NP) using SH-CD and $\mathrm{NH}_{2}-\beta-\mathrm{CD}$ functionalized Au@SiC (Au@CSiC$\mathrm{SH} / \mathrm{NH}_{2}-\mathrm{CD}$ ) nanocomposite was successfully constructed. Differential pulse voltammetry was used to quantify $0-N P$ and $p-N P$ within the concentration range of $0.01-150 \mu \mathrm{M}$ under the optimal conditions. The detection limit $(\mathrm{S} / \mathrm{N}=3$ ) of the sensor was 0.019 and $0.023 \mu \mathrm{M}$ for $0-\mathrm{NP}$ and $p$ - NP, respectively, indicating a low detection limit. Interference study results demonstrated that the sensor was not affected in the presence of similar aromatic compounds during the determination of NP isomers, showing high selectivity. The proposed electrochemical sensing platform was successfully used to determine NP isomers in tap water. The low detection limit and high selectivity of the proposed electrochemical sensor were caused by the high surface area, the excellent conductivity, and the more recognized (enriched) NP isomer molecules by $\mathrm{SH}-\beta-\mathrm{CD}$ and $\mathrm{NH}_{2}-\beta-\mathrm{CD}$ of the AuaCSiC-SH/NH $\mathrm{H}_{2}-\mathrm{CD}$ nanocomposite.
\end{abstract}

\section{Introduction}

Nitrophenol (NP) is a nitroaromatic compound with three isomers, $o$-nitrophenol $(o$-NP), $m$-nitrophenol $(m-\mathrm{NP})$ and $p$ nitrophenol ( $p$-NP), and is widely used as intermediates in the chemical industry, especially in the manufacture of paints, pesticides, explosives, medicines, and plasticizers. ${ }^{\mathbf{1 , 2}}$ On the other hand, some isomers of NP can be found in wastewater and agricultural run-off due to biodegradation of some organophosphorus pesticides. ${ }^{3}$ NPs are widely distributed not only in industrial wastewater and soil but also in freshwater and marine environments. ${ }^{4,5}$ It is well-known that the isomers of nitrophenol are serious environmental pollutants due to their potential toxicity (carcinogen, teratogenic and mutagenic) to human beings, animals, and plants even at a very low concentration. ${ }^{6-8}$ The harmful effects of NP on humans include headache, fever, breathing trouble, and even death at high levels of exposure. ${ }^{9}$ In addition, the NPs are readily accumulated in organisms and are hard to naturally degrade because of the

${ }^{a}$ School of Chemical Science and Technology, Yunnan University, Kunming 650091, PR China. E-mail: Lcppp1974@sina.com; Fax: +86-871-65031119; Tel: +86-87165031119

${ }^{b}$ International Center for Photoelectronic and Engergy Materials Research (MOST), Yunnan University, Kunming 650091, PR China

$\dagger$ Electronic supplementary information (ESI) available. See DOI: 10.1039/c7ra12715d high structure stability. ${ }^{\mathbf{1 0 , 1 1}}$ Therefore, NP has been listed as a priority pollutant by the United States Environmental Protection Agency (USEPA). ${ }^{\mathbf{1 2 , 1 3}}$ However, the toxicity of nitrophenol isomers is different; $o$-NP and $p$-NP are highly toxic and exhibit much more serious impact on the growth and metabolic activities of the organism. ${ }^{14,15}$ The permissible limit of NP in the environment has been given. For example, the permissible limit of $p$-NP in the environment by different agents like United States EPA and the European Commission are $0.43 \mu \mathrm{M}$ and $0.72 \mathrm{nM}$, respectively. ${ }^{16}$ Accordingly, it is highly desirable to develop a selective and sensitive analytical method for nitrophenol isomers for environmental monitoring and diagnostic research.

$\beta$-Cyclodextrin ( $\beta$-CD) is a kind of oligosaccharide composed of seven glucose units, which has a toroidal shape with a hydrophobic inner cavity and a hydrophilic exterior. ${ }^{\mathbf{1 6}}$ The hydrophobic inner cavity could enable $\beta$-CD molecules to bind selectively various organic, inorganic, and biological guest molecules in their cavities to form host-guest inclusion complexes. This supramolecular inclusion complexes has been proven to show high molecular recognition and enrichment capability. Furthermore, the exterior hydrophilicity could make $\beta$-CD easily to be used as functional molecules to improve the dispersibility (solubility) of functional materials. Meanwhile, $\beta$ $\mathrm{CD}$ is environmentally friendly and low-cost. ${ }^{17}$ Based on these interesting characteristics, $\beta$-CD has been widely used in field of 
electrochemical sensing. ${ }^{18-22}$ However, in most cases, $\beta$-CD was loaded on the material surface at one interface in only one way. ${ }^{17}$ It is desired that more $\beta$-CD molecules are linked with material through different binding sites at the same interface.

It is well-known that carbon materials are widely utilized in electrochemical sensor. Generally, carbon-based materials usually have higher background currents, which is a serious disadvantage, especially in electrochemical sensing or biosensing detection system. Alternatively, noncarbon materials commonly have lower background currents. ${ }^{23}$ As one of the most valuable noncarbon materials, silicon carbide (SiC) has been considered to be a promising metal nanoparticles (NPs) support material due to its high-temperature stability, hardness, as well as chemical inertness. ${ }^{24}$ This provide a hint that $\mathrm{SiC}$ could be an ideal substrate for further modification of function group or anchoring noble metal NPs for highperformance electrocatalytic or electrochemical devices.

To load more $\beta$-CD molecules with material and thus improve the enrichment capacity and electrochemical detection limit of guest molecule, in the present study, thiol- $\beta$-cyclodextrin (SH- $\beta$-CD) and mono-(6-ethanediamine-6-deoxy)- $\beta$-cyclodextrin $\left(\mathrm{NH}_{2}-\beta-\mathrm{CD}\right)$ were grafted with silicon carbide (SiC) by $\mathrm{Au}-\mathrm{S}$ bond and amido bond, respectively. Then, an electrochemical sensor based on the $\beta-\mathrm{CD} / \mathrm{SiC}$ composite modified glassy carbon electrode (GCE) was fabricated for sensitive detection of nitrophenol isomers. The proposed electrochemical sensing platform was used to recognize guest molecules (NP isomers) as illustrated in Scheme 1.

\section{Materials and methods}

The experimental details are provided in ESI. $\dagger$

\section{Results and discussion}

\subsection{Characterization of the Au@CSiC and Au@CSiC-SH/ $\mathrm{NH}_{2}-\mathrm{CD}$ materials}

The morphologies and microstructures of the Au@CSiC were investigated using a TEM. Fig. 1A-C shows the TEM images of the Au@CSiC at different magnifications. SiC NPs demonstrated large amounts of particles approximately $20 \mathrm{~nm}$. The Au NPs as spherical particles with a uniform size of $\sim 5 \mathrm{~nm}$ were fairly well monodispersed on the surface of SiC. Compared with Fig. 1A, B and C, shows that the surface of SiC was covered a layer of amorphous carbon with a thickness of $\sim 15 \mathrm{~nm}$ after a hydrothermal reaction in glucose aqueous solution, forming a clear core-shell structure. These results indicated the $\mathrm{Au} @ \mathrm{CSiC}$ nanocomposite was successfully prepared. Au@CSiC$\mathrm{SH} / \mathrm{NH}_{2}-\mathrm{CD}$ nanohybrids also were further characterized by FTIR and TGA. Fig. 1D shows the FTIR spectra of SiC, CSiC, and $\mathrm{Au} @ \mathrm{CSiC}-\mathrm{SH} / \mathrm{NH}_{2}-\mathrm{CD}$ respectively. The FTIR spectrum of $\mathrm{SiC}$ exhibited typical $\mathrm{C}-\mathrm{Si}$ stretching vibrations at $824 \mathrm{~cm}^{-1}$. The strong peaks at 3435 and $1630 \mathrm{~cm}^{-1}$ were ascribed to stretching vibrations and bending vibrations of $\mathrm{O}-\mathrm{H}$ in water adsorbed by SiC samples, respectively. In the case of CSiC, the weak peak at $1728 \mathrm{~cm}^{-1}$ corresponds to the $\mathrm{C}=\mathrm{O}$ stretching vibrations, which indicates the successful functionalization of the SiC with

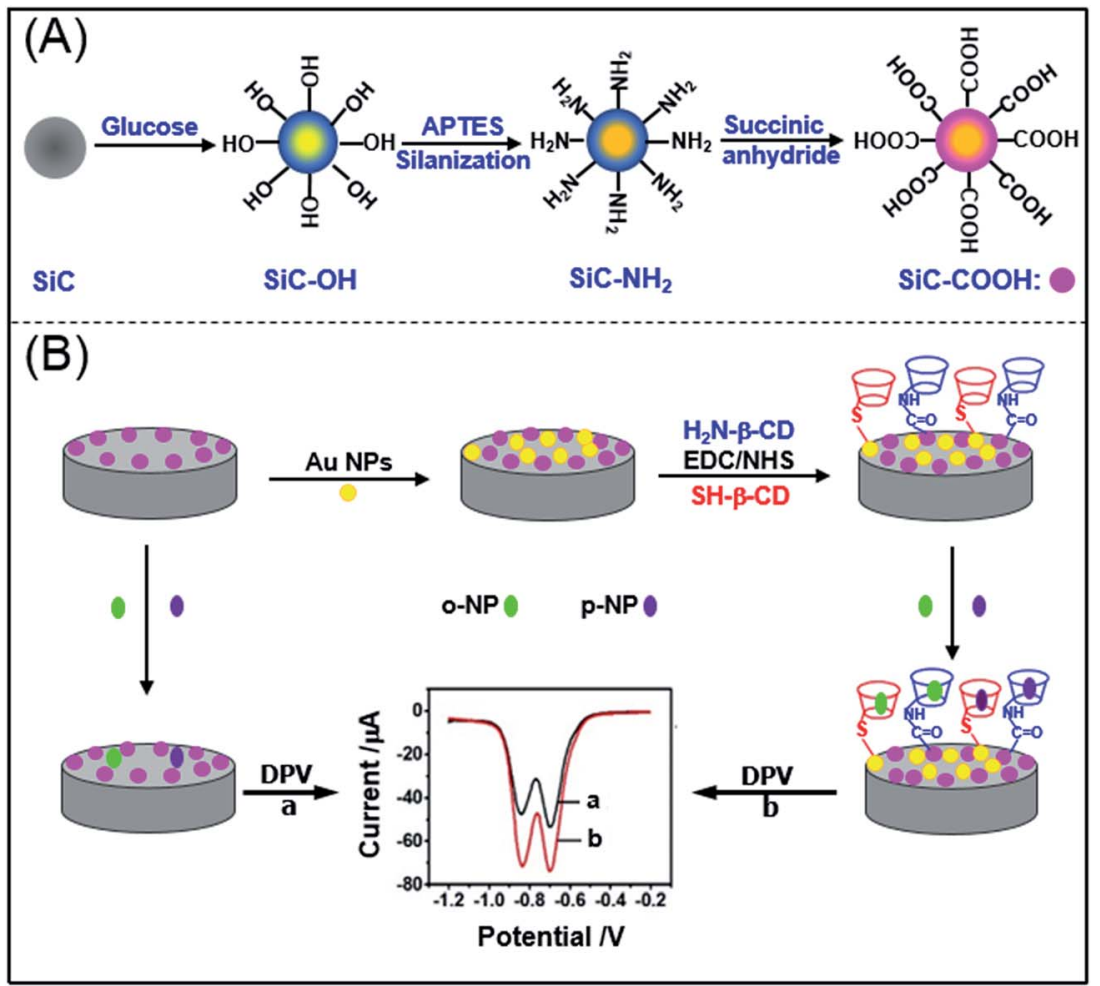

Scheme 1 The illustration of electrochemical sensing strategy for nitrophenol isomers based on $\beta$-cyclodextrin derivatives functionalized silicon carbide. (A) Synthesis of carboxyl silicon carbide (CSiC). (B) Fabrication of the modified electrodes. 

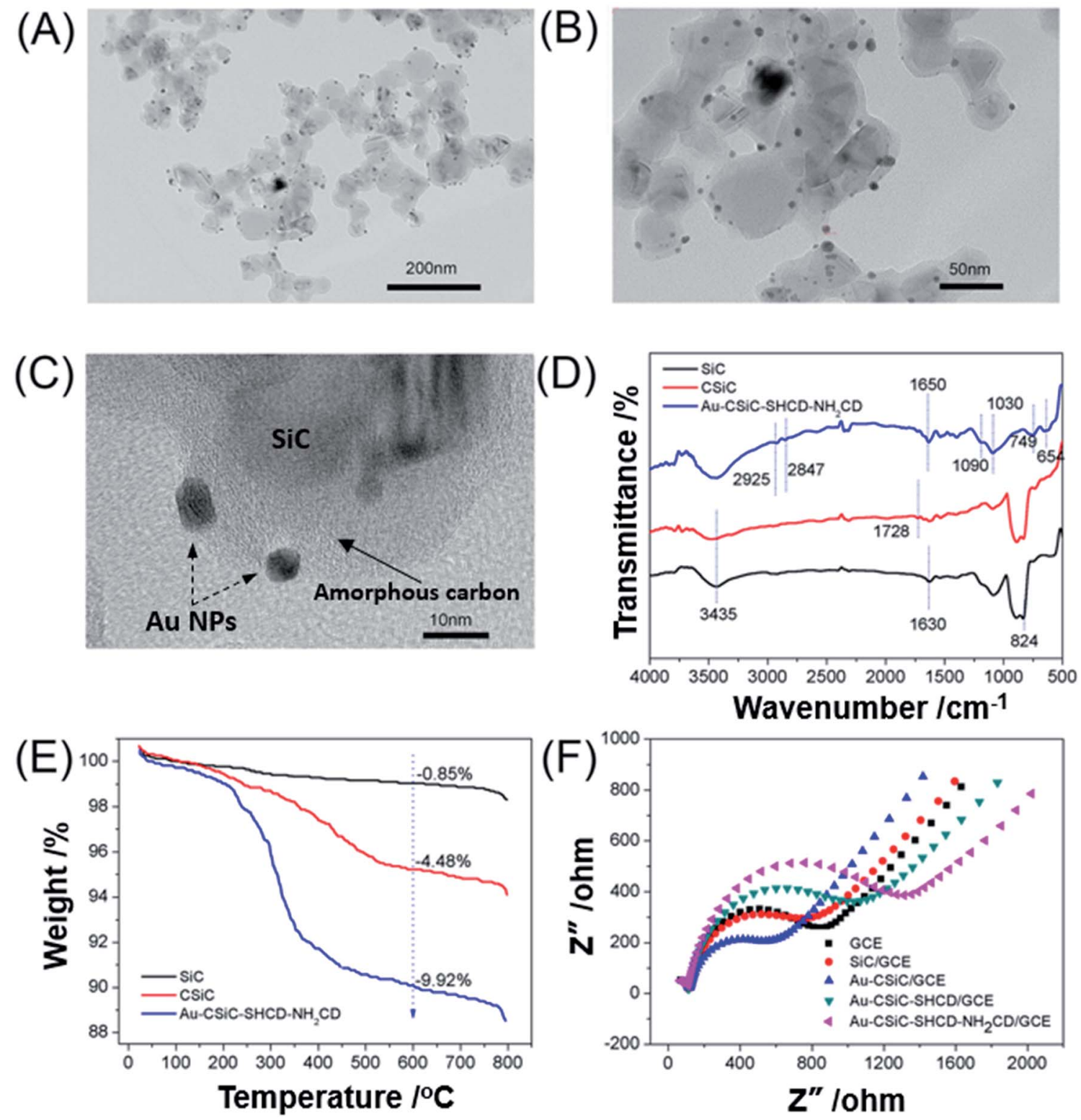

Fig. 1 Characterization of the Au@CSiC and Au@CSiC-SH/NH $2-C D$ materials. (A, B, C) TEM images of Au@CSiC at different magnifications; (D) FTIR spectra of $\mathrm{SiC}, \mathrm{CSiC}$, and Au@CSiC-SH/NH$-\mathrm{CD}$; (E) TGA curves of SiC, CSiC, and Au@CSiC-SH/NH ${ }_{2}-\mathrm{CD}$; (F) EIS characterization of bare GCE, SiC/GCE, Au-SiC/GCE/GCE, Au-SiC-SHCD/GCE, and Au-SiC-SH/NH $\mathrm{N}_{2}-\mathrm{CD} / \mathrm{GCE}$ using $2.0 \mathrm{mM}\left[\mathrm{Fe}(\mathrm{CN})_{6}\right]^{3-/ 4-}$ redox couple (1: 1) with $0.1 \mathrm{M} \mathrm{KCl}$ as supporting electrolyte.

carboxyl groups. It is noted that the FTIR spectrum of Au@CSiC$\mathrm{SH} / \mathrm{NH}_{2}-\mathrm{CD}$ exhibits typical $\beta-\mathrm{CD}$ absorption features of the ring vibrations at 654 and $749 \mathrm{~cm}^{-1}$, the coupled $\mathrm{C}-\mathrm{O}-\mathrm{C}$ stretching/ $\mathrm{O}-\mathrm{H}$ bending vibrations at $1030 \mathrm{~cm}^{-1}$ and $1090 \mathrm{~cm}^{-1},-\mathrm{CH}_{2}$ stretching vibrations at $2925 \mathrm{~cm}^{-1}$, and $\mathrm{O}-\mathrm{H}$ stretching vibrations at $3435 \mathrm{~cm}^{-1}$. In addition, peaks at $1650 \mathrm{~cm}^{-1}$ may be attributed to the $\mathrm{C}=\mathrm{O}$ of amide groups. The results suggested that the $\beta$-CD molecules were successfully attached to CSiC. ${ }^{\mathbf{1 7 2 1}}$ The thermal stability of $\mathrm{SiC}, \mathrm{CSiC}$, and $\mathrm{Au} @ \mathrm{CSiC}-\mathrm{SH} / \mathrm{NH}_{2}-\mathrm{CD}$ was investigated by TGA. As shown in Fig. 1E, for the pristine $\mathrm{SiC}$, there is almost no weight loss in the measured temperature range of $35-800{ }^{\circ} \mathrm{C}$. In the case of CSiC, an obvious mass loss can be seen at $400-700{ }^{\circ} \mathrm{C}$, which is due to the decomposition of the surface carboxyl groups on SiC. A 4.48 wt\% loss was observed when the temperature was approximately $600{ }^{\circ} \mathrm{C}$. The $\mathrm{Au} @ \mathrm{CSiC}-\mathrm{SH} / \mathrm{NH}_{2}-\mathrm{CD}$ exhibited an abrupt mass loss when the temperature increased to approximately $200{ }^{\circ} \mathrm{C}$ because of the decomposition of $\mathrm{SH}-\beta-\mathrm{CD}$ and $\mathrm{NH}_{2}-\beta-\mathrm{CD}$; the mass loss reached approximately $9.92 \mathrm{wt} \%$ when the temperature was $600{ }^{\circ} \mathrm{C}$, indicating that $\mathrm{SH}-\beta-\mathrm{CD}$ and $\mathrm{NH}_{2}-\beta-\mathrm{CD}$ were successfully linked to the CSiC.

\subsection{Electrochemical behaviors of NP isomers using the modified electrodes}

EIS was performed at the potential of $0.1 \mathrm{~V}$ and the frequency ranges was from $10^{1}$ to $10^{5} \mathrm{~Hz}$, using $2.0 \mathrm{mM}\left[\mathrm{Fe}(\mathrm{CN})_{6}\right]^{3-/ 4-}$ 
redox couple $(1: 1)$ with $0.1 \mathrm{M} \mathrm{KCl}$ as supporting electrolyte. The value of the electron-transfer resistance $\left(R_{\mathrm{ct}}\right)$ of the modified electrode was estimated by the semicircle diameter. Fig. $1 \mathrm{~F}$ illustrates the EIS of the bare GCE (a), CSiC/GCE (b), Au@CSiC/ GCE (c), Au@CSiC-SHCD/GCE (d) and Au@CSiC-SH/NH $-\mathrm{CD} /$ GCE (e). Obviously, the bare GCE exhibited a semicircle portion and the value of $R_{\mathrm{ct}}$ was estimated to be approximately $850 \Omega$. When CSiC was loaded on the bare GCE, the $R_{\text {ct }}$ value of the GCE decreased to $750 \Omega$, indicating that CSiC had good conductivity and improved obviously the diffusion of ferricyanide toward the electrode interface. ${ }^{25}$ When the Au@CSiC was modified on the bare GCE, the $R_{\mathrm{ct}}$ value decreased comparing with that of $\mathrm{CSiC}$, revealing that Au NPs with excellent conductivity can facilitate the electron transfer. For the $\mathrm{Au} @ \mathrm{CSiC}-\mathrm{SHCD} / \mathrm{GCE}$ and $\mathrm{Au} @ \mathrm{CSiC}-\mathrm{SH} / \mathrm{NH}_{2}-\mathrm{CD} / \mathrm{GCE}$, their semicircles both increased to approximately 1100 and $1300 \Omega$. This is because of the $\mathrm{SH}-\mathrm{CD}$ or $\mathrm{NH}_{2}$-CD molecule hindered the electron transfer and made the interfacial charge transfer difficult. These results further suggested that two $\beta$-CD derivatives have been successfully attached to the SiC, which were agree well with the results of IR and TGA.

The electrochemical responses of $o$-NP and $p$-NP at different modified electrodes were investigated using CVs. The CVs for the oxidation of $1.0 \mathrm{mM} o-\mathrm{NP}$ and $p$-NP at bare GCE (a), CSiC/ GCE (b), Au@CSiC/GCE (c), Au-CSiC-SHCD/GCE (d), Au@C$\mathrm{SiC}-\mathrm{SH} / \mathrm{NH}_{2}-\mathrm{CD} / \mathrm{GC}$ (e) were carried out in 0.1 M PBS (pH 6.0). As shown in Fig. 2A and B, only a well-defined reduction peak is observed during the sweep from $-1.2 \mathrm{~V}$ to $-0.2 \mathrm{~V}$ at all the electrodes, and no corresponding oxidation peaks are observed, indicating that the electrode response of $o$-NP and $p$-NP is a typical irreversible electrode reaction. ${ }^{16}$ The $o$-NP and $p$-NP exhibit a clear cathodic peak at approximately -0.72 and $-0.83 \mathrm{~V}$, respectively, which are associated with the irreversible reduction process of nitryl in aqueous solution. ${ }^{28,30}$ Furthermore, enhanced reduction currents of $o$-NP and $p$-NP using the CSiC/GCE were observed in comparison with those in the bare GCE. Meanwhile, the peak potential of $o$-NP and $p$-NP in CSiC/ GCE exhibited slight negative shift $(\sim 30 \mathrm{mV})$ than GCE. These results may be caused by good catalytic activity of CSiC. ${ }^{24}$ After the homogeneous $\mathrm{Au}$ NPs were monodispersed on the CSiC surface, the reduction currents of $o-\mathrm{NP}$ and $p$-NP further increased compared with $\mathrm{CSiC}$, which could be ascribed to the fact that Au NPs with remarkable conductivity and large surface area could amplify the electrochemical signal. On the other hand, the reduction peak current of $o$-NP and $p$-NP at Au@CSiCSHCD/GCE is larger than that at Au@CSiC/GCE, suggesting that $\beta$-CD molecule has good recognition capability and thus cause the excellent enrichment capacity of $o$-NP and $p$-NP. Interestingly, the reduction peak current of the NP isomers at Au@CSiC-SH/ $\mathrm{NH}_{2}-\mathrm{CD} / \mathrm{GCE}$ further increased markedly compared with that at $\mathrm{Au} @ \mathrm{CSiC}-\mathrm{SHCD} / \mathrm{GCE}$, indicated that dual $\beta$-CD derivatives were functionalized at the same electrode interface and successfully used to improve the current signal of the NP isomers.

The DPVs for the reduction of a mixture containing $1 \mathrm{mM}$ of $o$-NP and $p$-NP at bare GCE (a), CSiC/GCE (b), Au@CSiC/GCE (c), $\mathrm{Au} @ \mathrm{CSiC}-\mathrm{SH}-\mathrm{CD} / \mathrm{GCE}$ (d) and Au@CSiC-SH/NH${ }_{2}-\mathrm{CD} / \mathrm{GCE}$ (e) were performed in 0.1 M PBS (pH 6.0). As shown in Fig. 2C, the current amplification and potential movement direction are similar to the CV diagram. The two well-defined peaks at -0.70 and $-0.85 \mathrm{~V}$ correspond to $o$-NP and $p$-NP, respectively; ${ }^{30}$ these peaks are well separated and show a potential difference of $150 \mathrm{mV}$, which is an adequately large window for simultaneously determining the concentrations of mixed solutions of $o$ $\mathrm{NP}$ and $p$-NP. The reduction peak currents of $o$-NP and $p$-NP at the modified electrodes increased in sequence, indicating that the Au@CSiC-SH/ $\mathrm{NH}_{2}$-CD/GCE is suitable for the electrochemical sensing of $o$-NP and $p$-NP. Although the $\beta$-CD macrocyclic host is non-conducting and unfavorable for the electron transfer, the reduction current of $o$-NP and $p$-NP also enhanced obviously. It is worthy to note that $\beta$-CD molecule has a hydrophobic inner cavity and a hydrophilic exterior. Nitrophenol could enter the hydrophobic inner cavity of $\beta-\mathrm{CD}$ and form a stable host-guest inclusion with $o$-NP and $p$-NP through supramolecular recognition interactions. Hence, large amount of guest molecules were enriched on the surface of the modified electrode, leading to the significant enhancement of the reduction peak current of $o$-NP or $p$-NP. Meanwhile, hydrophilic exterior of $\beta$-CD molecule could make $\beta$-CD modified CSiC into a composite with good dispersibility in aqueous solution. Such strategy of loading different supramolecular host derivatives to material and therefore enhances the molecular enrichment capability is also expected to be used in sensors for sensitive electrochemical determination of other analytes.

\subsection{Optimization of experimental conditions}

The $\mathrm{pH}$ value of the detection medium could affect the rate of mass transport to the electrode surface, especially when the redox process involves several protons. ${ }^{15}$ The effect of $\mathrm{pH}$ on the current response of the Au@CSiC-SH/ $\mathrm{NH}_{2}-\mathrm{CD}$ toward $1 \mathrm{mM}$ NP was investigated within the $\mathrm{pH}$ range of 4.0-8.0. Fig. 2D shows that the reduction peak current gradually increases with the increased $\mathrm{pH}$ from 4.0 to 6.0 , which was attributed to the high concentration of protons in the solution. ${ }^{30}$ These protons replaced the molecules of nitrophenol isomers that were present on the adsorption sites on the $\mathrm{Au} @ \mathrm{CSiC}-\mathrm{SH} / \mathrm{NH}_{2}$-CD/GCE surface. However, further increase in $\mathrm{pH}$ caused a decrease in the reduction peak current because of the nitro anions that prevented the access of phenol compounds to the adsorption sites on the Au@CSiC-SH/ $\mathrm{NH}_{2}$ CD/GCE surface. Therefore, $\mathrm{pH} 6.0$ was selected as the optimal solution $\mathrm{pH}$ for the simultaneous determination of $o$ $\mathrm{NP}$ and $p$-NP. On the other hand, it is a general rule that a conjugate base is oxidized at less positive potentials than the corresponding acid form. A conjugate base is always more easily oxidized than the corresponding acid form, the anodic current accompanied by an antecedent acid-base equilibrium therefore always increases with increasing $\mathrm{pH}$ values. The observed decrease of the cathode current with increasing $\mathrm{pH}$ thus cannot be attributed to an acid-base reaction occurring before the electron uptake. In this study, the optimal $\mathrm{pH}$ of 6.0 was is considered to be the result of the synergistic effect of the above as-mentioned two reasons. 

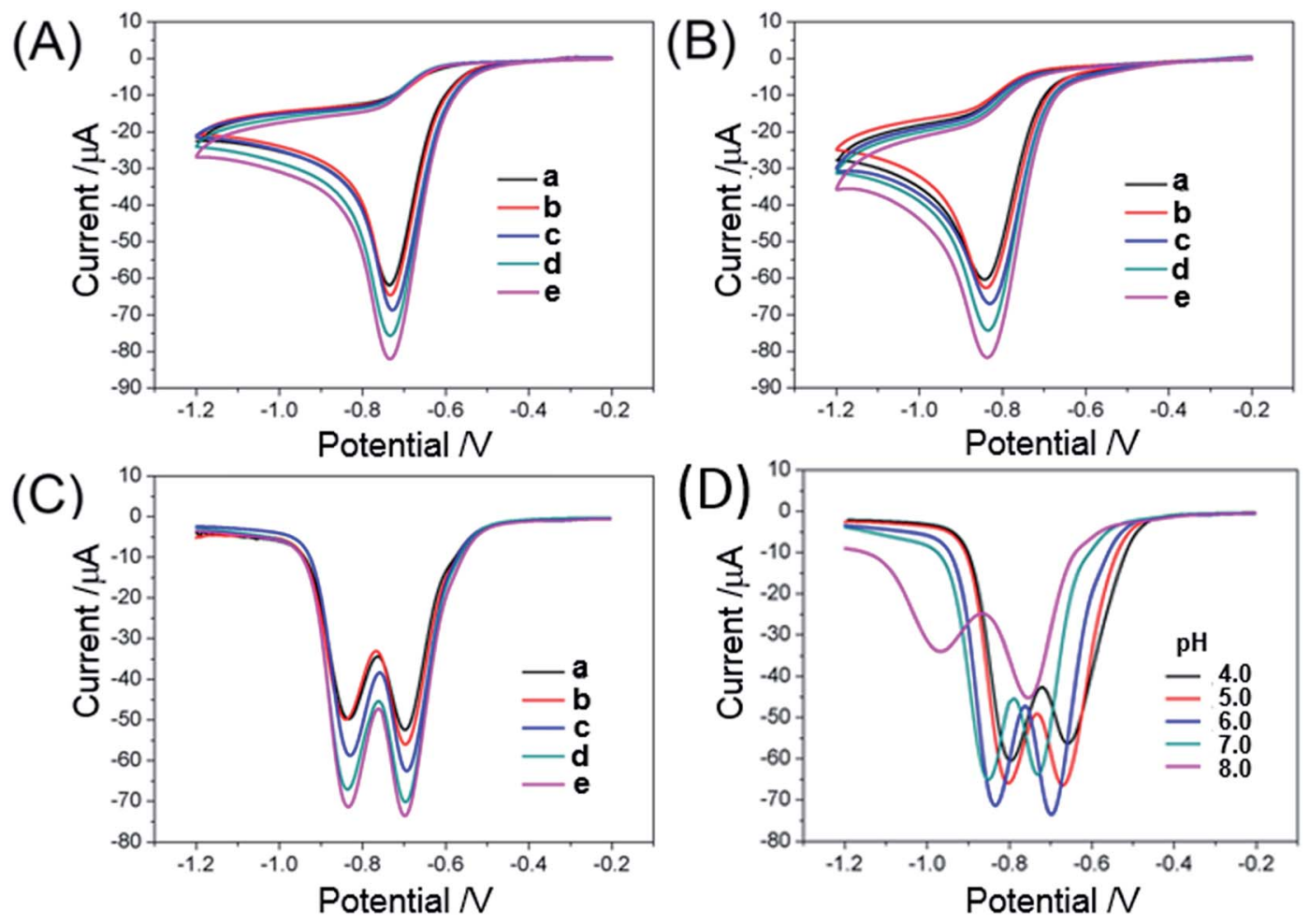

Fig. 2 CVs of $1.0 \mathrm{mM}$ o-NP (A) and $1.0 \mathrm{mM} \mathrm{p-NP(B)}$ at bare GCE (a), CSiC/GCE (b), Au-CSiC/GCE (c), Au-CSiC-SHCD/GCE (d), and Au-CSiC$\mathrm{SH} / \mathrm{NH}_{2}-\mathrm{CD} / \mathrm{GCE}$ (e) in $0.1 \mathrm{M}$ PBS solution (pH 6.0); (C) DPVs obtained for the oxidation of $0.1 \mathrm{mM}$ of $o-\mathrm{NP}$ and $p-\mathrm{NP}$ at bare GCE (a), CSiC/GCE (b), Au-CSiC/GCE (c), Au-CSiC-SHCD/GCE (d), and Au-CSiC-SH/NH ${ }_{2}-\mathrm{CD} / \mathrm{GCE}$ (e); (D) effect of detection medium pH on the oxidation peak currents of $1.0 \mathrm{mM}$ o-NP and $p-\mathrm{NP}$ at Au-CSiC-SH/NH $\mathrm{N}_{2} \mathrm{CD} / \mathrm{GCE}$ in $0.1 \mathrm{M} \mathrm{PBS}$ (pH 6.0) by DPV. Pulse width: $0.05 \mathrm{~s}$; amplitude: $0.05 \mathrm{~V}$.

The accumulation step is a simple and effective strategy to enhance sensitivity. Thus, the effects of accumulation time and potential on the $\mathrm{Au} @ \mathrm{CSiC}-\mathrm{SH} / \mathrm{NH}_{2}$-CD/GCE sensor were investigated. The effect of accumulation potential on the reduction peak currents of NP isomers was also investigated. Fig. 3A shows that reduction peak currents gradually increase with increasing accumulation times of up to $150 \mathrm{~s}$ and then level off thereafter, which indicates that accumulation of $o$-NP and $p$-NP on the Au@CSiC-SH/ $\mathrm{NH}_{2}-\mathrm{CD} / \mathrm{GCE}$ can rapidly reach saturation.
Fig. 3B shows that the highest reduction peak current is achieved at $0 \mathrm{~V}$. The reduction peak currents of $o$-NP and $p$-NP were compared at different accumulation time. Accordingly, in the present study, the accumulation step was performed at $0 \mathrm{~V}$ for $150 \mathrm{~s}$.

The effect of scan rate on the reduction of $o$-NP and $p$-NP was investigated. Fig. $4 \mathrm{~A}$ and $\mathrm{B}$ show the CVs of $1 \mathrm{mM} o$-NP and $p$-NP on $\mathrm{Au} @ \mathrm{CSiC}-\mathrm{SH} / \mathrm{NH}_{2}-\mathrm{CD} / \mathrm{GCE}$ for different scan rates. The reduction peak current of NP isomers increases gradually with
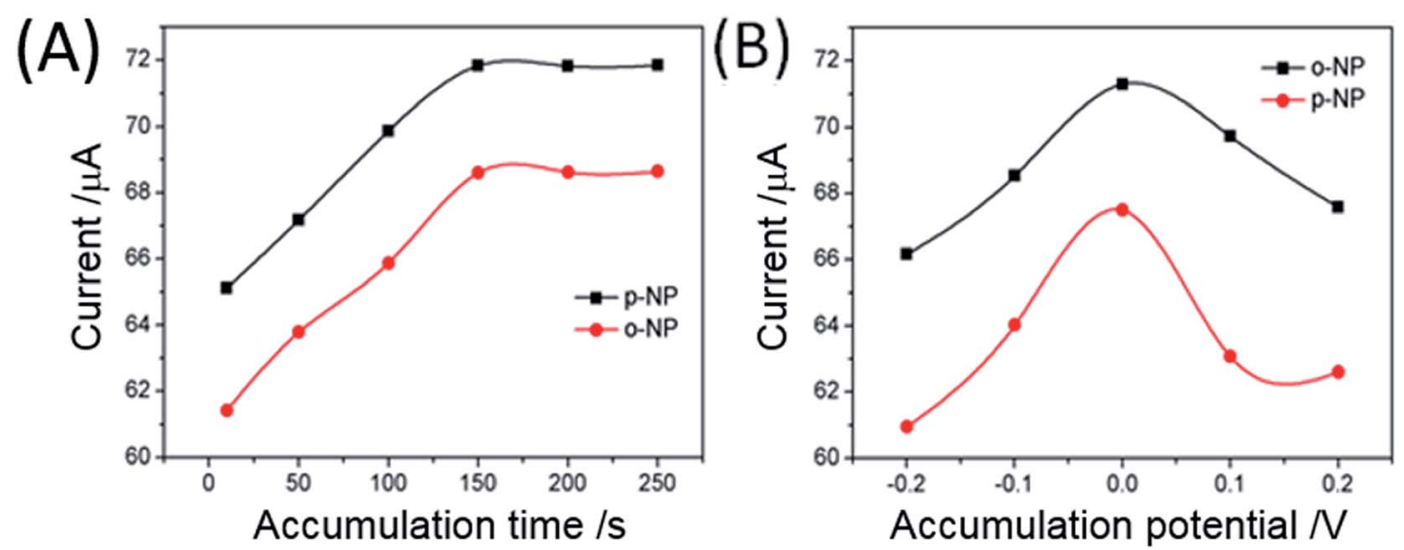

Fig. 3 Effect of accumulation time (A) and accumulation potential (B) on the reduction peak current of $1 \mathrm{mM} o-\mathrm{NP}$ and $p-\mathrm{NP}$ at $\mathrm{Au}-\mathrm{CSiC}-\mathrm{SH} /$ $\mathrm{NH}_{2} \mathrm{CD} / \mathrm{GCE}$ in $0.1 \mathrm{M}$ PBS (pH 6.0) by DPV. Pulse width: $0.05 \mathrm{~s}$; amplitude: $0.05 \mathrm{~V}$. 

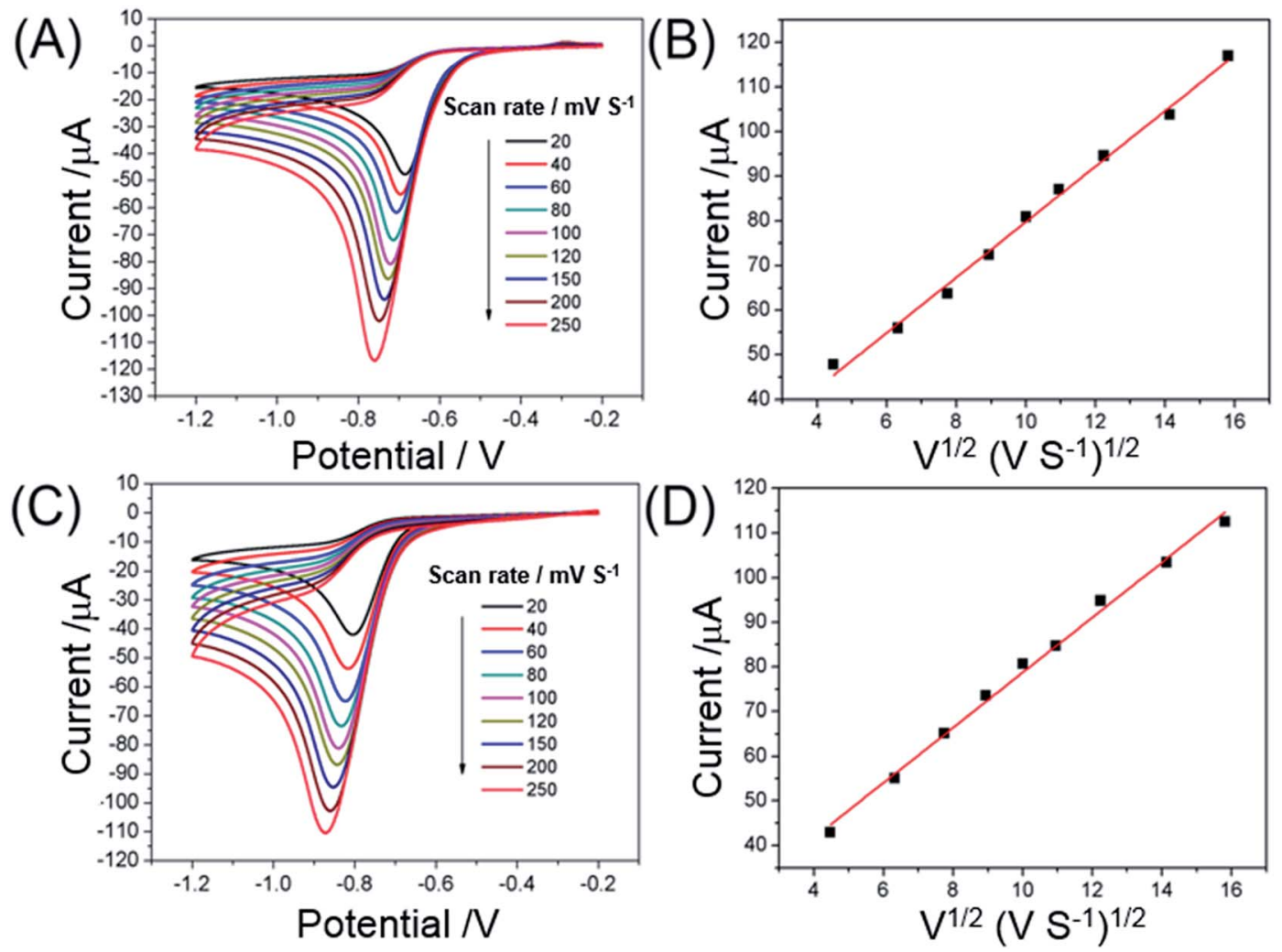

Fig. 4 CVs obtained of the reduction of $1 \mathrm{mM}$ o-NP (A, B) and $p-N P(C, D)$ at Au-CSiC-SH/NH ${ }_{2} C D / G C E$ in $0.1 \mathrm{M} \mathrm{PBS} \mathrm{(pH} \mathrm{6.0)} \mathrm{at} \mathrm{various} \mathrm{scan}$ rates $20,40,60,80,100,120,150,200$, and $250 \mathrm{mV} \mathrm{s}^{-1}$; magnitude of reduction peak current vs. square root of scan rate.

an increase of scan rate. The reduction peak current increases linearly with the square root of scan rate in the range of 20 to $250 \mathrm{mV} \mathrm{s}^{-1}$, and the equation can be expressed as $I_{o-\mathrm{NP}}(\mu \mathrm{A})=$ $6.201 \nu^{1 / 2}\left(\mathrm{mV} \mathrm{s}^{-1}\right)^{1 / 2}+16.617\left(R^{2}=0.9941\right)$ and $I_{p-\mathrm{NP}}(\mu \mathrm{A})=$ $6.215 \nu^{1 / 2}\left(\mathrm{mV} \mathrm{s}^{-1}\right)+17.634\left(R^{2}=0.9942\right)$, indicating that the reduction of $o$-NP and $p$-NP at $\mathrm{Au} @ \mathrm{CSiC}-\mathrm{SH} / \mathrm{NH}_{2}-\mathrm{CD} / \mathrm{GCE}$ may be a diffusion-controlled process. ${ }^{28}$ Usually, low scan rate results in a small peak current and but a long measuring time. Although high scan rate results in a large peak current, the background of peak current also increases, which affected the stability of electrochemical sensor. Therefore, $100 \mathrm{mV} \mathrm{s}^{-1}$ is selected as the optimal scan rate for the determination of $o$-NP and $p$-NP. In this work, $\beta$-CD molecule was used as a factor to recognize and enrich more guest molecule (NP isomers) and thus improve the current signal of NP. Usually, $\beta$-CD molecule recognizes the most guest molecules by taking some time to reach an equilibrium state. In this study, a host-guest complex of $\beta$-CD and NP was formed and the load transfer of electrons proceeds cannot be governed by pure diffusion process. In view of the enrichment of NP by $\beta$-CD, the electrochemical reaction may be a process of mixed controls of diffusion and adsorption.

\subsection{Simultaneous electrochemical determination of $o$-NP and $p$-NP using DPV}

DPV was used to simultaneously quantify the $o$-NP and $p$-NP under the optimal conditions. Fig. 5A shows the DPV curves of $o$-NP and $p$-NP on the Au@CSiC-SH/NH ${ }_{2}-\mathrm{CD} / \mathrm{GCE}$ at different concentrations. The reduction peak current increased with the increased concentration of $o$-NP and $p$-NP. The reduction currents were proportional to the $o$-NP concentrations in the range of $0.01-5.00$ and $5.00-150.00 \mu \mathrm{M}$, respectively, with a detection limit of $0.019 \mu \mathrm{M}(\mathrm{S} / \mathrm{N}=3)$. The corresponding regression equations were calculated as $I_{o-\mathrm{NP}}(\mu \mathrm{A})=0.96 C_{o-\mathrm{NP}}(\mu \mathrm{M})+3.17$ and $I_{o-\mathrm{NP}}(\mu \mathrm{A})=0.075 C_{o-\mathrm{NP}}(\mu \mathrm{M})+7.79$ (Fig. 5B). Fig. $5 \mathrm{C}$ shows the corresponding calibration curve for $p$-NP. The reduction currents were also proportional to the concentration of $p$-NP in the range of $0.01-5.00$ and $5.00-150.0 \mu \mathrm{M}$, respectively, with a detection limit of $0.023 \mu \mathrm{M}(\mathrm{S} / \mathrm{N}=3)$. The corresponding regression equations were calculated as $I_{p \text {-NP }}(\mu \mathrm{A})=0.81 C_{p \text {-NP }}$ $(\mu \mathrm{M})+2.59$ and $I_{p-\mathrm{NP}}(\mu \mathrm{A})=0.076 C_{p-\mathrm{NP}}(\mu \mathrm{M})+6.58$, respectively. The performance of the proposed $\mathrm{Au} @ \mathrm{CSiC}-\mathrm{SH} / \mathrm{NH}_{2}-\mathrm{CD}$ modified electrode was compared with those of other reported electrodes.

\subsection{Molecular docking}

To gain an insight into the binding modes of host-guest, molecular docking was performed to study the $\beta-\mathrm{CD} / o-\mathrm{NP}$ and $\beta$-CD $/ p$-NP inclusion complexes. The binding modes of $\beta$ - $\mathrm{CD} / o^{-}$ $\mathrm{NP}$ and $\beta-\mathrm{CD} / p$-NP were simulated using the DOCK6 program and shown in Fig. 6 . The docking scores and binding free energy of $\beta$-CD $/ o-\mathrm{NP}$ and $\beta-\mathrm{CD} / p$-NP were also obtained and provided in Tables 1 and 2, respectively. Generally, if the binding energy is more negative, the interaction between the host and guest will be stronger. The results showed that the molecular docking and 

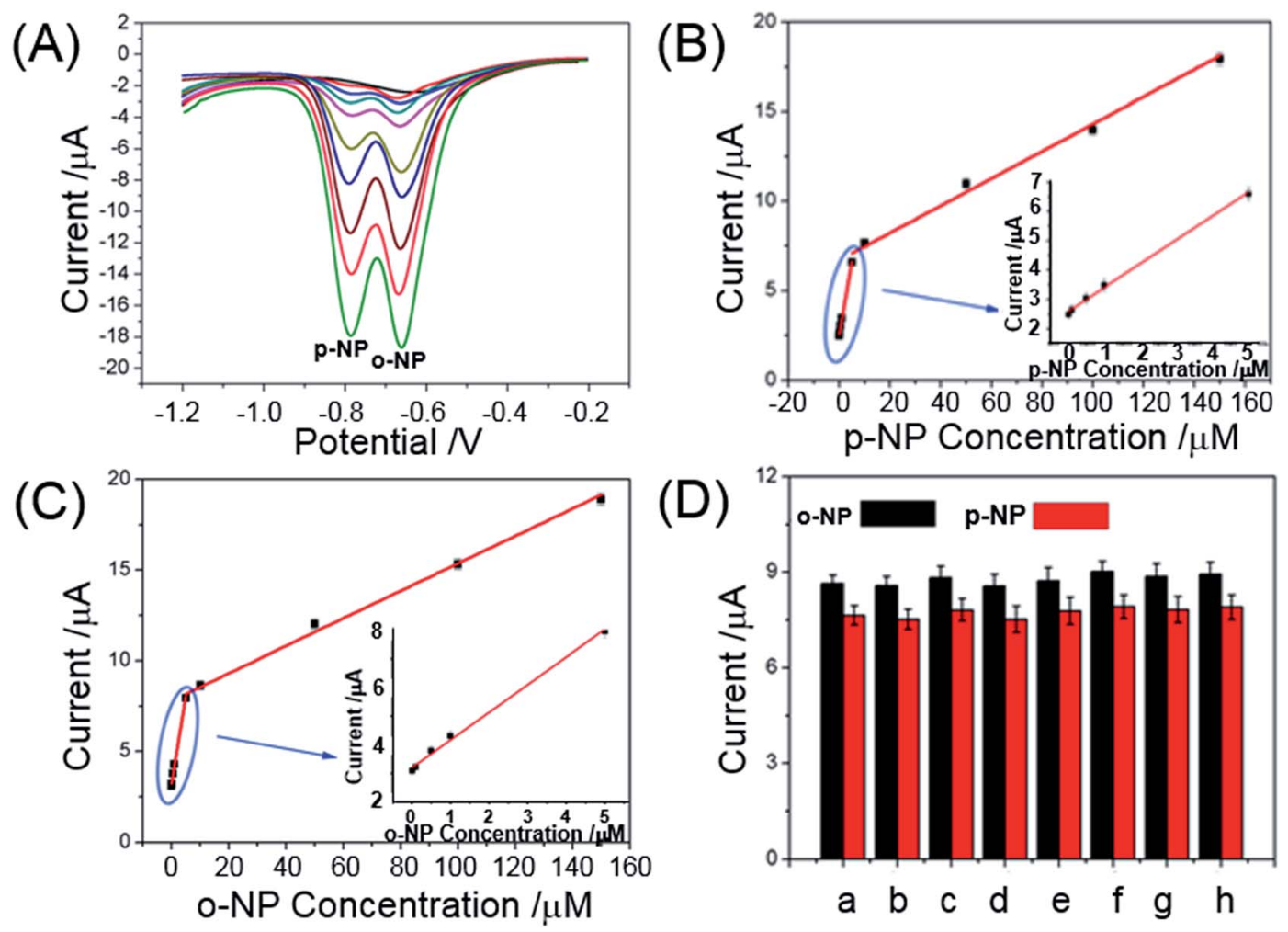

Fig. 5 Quantitative analysis performance of the $\mathrm{Au}-\mathrm{CSiC}-\mathrm{SH} / \mathrm{NH}_{2} \mathrm{CD} / \mathrm{GCE}$ sensor. Determination of solutions containing different concentrations of $o-N P$ and $p-N P(A)$. Concentrations of $o-N P$ and $p$-NP: $0.00,0.01,0.1,0.5,1,5,10,50,150 \mu \mathrm{M}$. Calibration curves for simultaneous determination of $o-N P(B)$ and $p-N P(C)$ using the proposed sensor. The error bars represent the standard deviations of three parallel tests; (D) the reduction currents of $10 \mu \mathrm{M} o-\mathrm{NP}$ and $p$-NP in the absence (a) and presence of 20 -fold concentration of interfering species (from $b$ to h): phenol, paracetamol, catechol, hydroquinone, 2,4-dinitrophenol, glucose, and citric acid.

energy optimization conformations of $\beta$ - $\mathrm{CD} / o$-NP were similar before and after optimization, suggesting a signal binding mode. The guest molecule was embedded in the cavity of $\beta$-CD and the nitro group of $o$-NP faced to the big ring of host (Table
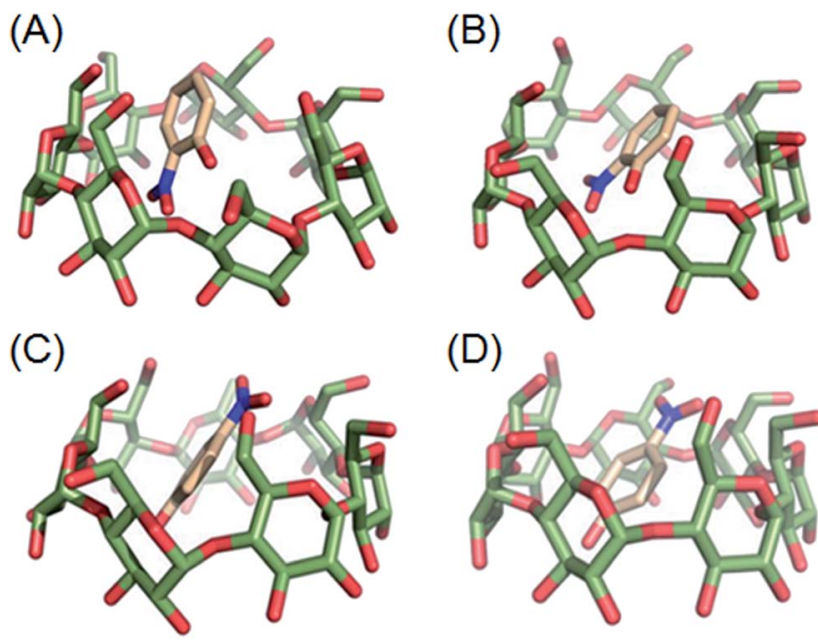

(D)

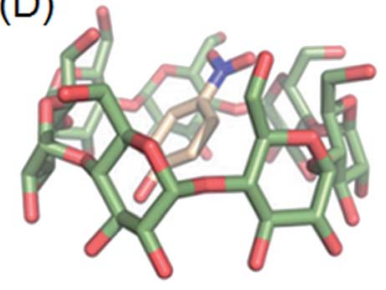

Fig. 6 Binding modes of $\beta-C D / o-N P$ and $p-N P / p-N P$ complexes by molecular docking. (A, B) Molecular docking conformation and energy optimization conformation of $\beta-\mathrm{CD} / \mathrm{O}-\mathrm{NP}$; (C, D) molecular docking conformation and energy optimization conformation of $\beta-C D / p-N P$.
1), where hydrophobic interaction may play an important role in the stabilization of the host-guest inclusion complex. As shown in Table 2, the $\Delta G_{\mathrm{vdw}}\left(-20.5390 \mathrm{kcal} \mathrm{mol}^{-1}\right)$ was much higher than $\Delta G_{\text {ele }}\left(-2.5308 \mathrm{kcal} \mathrm{mol}^{-1}\right)$ in the $\beta$-CD/o-NP host-guest inclusion, indicated that hydrophobic interaction made the more contribution than electrostatic force for the formation of the host-guest inclusion complex. Also, there were obvious positive polar solvation interaction contribution (7.6752 kcal $\left.\mathrm{mol}^{-1}\right)$ and negative nonpolar solvation

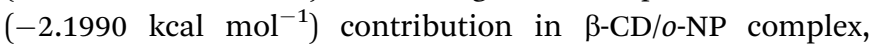
indicated that the hydrophobic interaction was favorable to the host-guest binding each other. Thus, the hydrophobic interaction was considered to be the major contribution for the formation of the $\beta-\mathrm{CD} / o-\mathrm{NP}$ inclusion complex. In the case of $\beta$ $\mathrm{CD} / p$-NP complex, the similar binding interaction (hydrophobic interaction) was found to be contributed to the formation of the host-guest inclusion complex. However, the binding interaction $\beta-\mathrm{CD} / o-\mathrm{NP}$ complex was slightly stronger than that of $\beta-\mathrm{CD} /$ $p$-NP complex. Unlike the case of $\beta$-CD/o-NP complex, the nitro group of $p$-NP faced to small ring of $\beta$-CD. The binding orientation of $o$-NP to $\beta$-CD was different from that $p$-NP to $\beta$-CD, which is considered to be the reason that caused the different binding interactions between $o-\mathrm{NP} / p$-NP and $\beta$-CD. Overall, $o$ $\mathrm{NP}$ and $p$-NP molecules entered into cavity of $\beta$-CD molecule and formed a stable host-guest complex. Although a "stable" host-guest inclusion complex formed, which is considered to 
Table 1 Molecular docking scores of $\beta-C D / o-N P$ and $\beta-C D / p-N P$ complexes $^{a}$

\begin{tabular}{|c|c|c|c|c|c|c|}
\hline Host & Guest & Pose & $\begin{array}{l}\text { Grid score } \\
\left(\mathrm{kcal} \mathrm{mol}^{-1}\right)\end{array}$ & $\begin{array}{l}\text { Grid_vdw } \\
\left(\text { kcal mol }^{-1}\right)\end{array}$ & $\begin{array}{l}\text { Grid_es } \\
\left(\mathrm{kcal} \mathrm{mol}^{-1}\right)\end{array}$ & $\begin{array}{l}\text { Int_en } \\
\left(\mathrm{kcal} \mathrm{mol}^{-1}\right)\end{array}$ \\
\hline \multirow[t]{3}{*}{$\beta-C D$} & $o-\mathrm{NP}$ & 1 & -24.156046 & -24.320509 & 0.164463 & 6.993269 \\
\hline & & 3 & -23.850988 & -23.947292 & 0.096304 & 6.993220 \\
\hline & $p$-NP & 1 & -24.025131 & -24.003979 & -0.021152 & 0.029970 \\
\hline
\end{tabular}

${ }^{a}$ vdw: van der Waals force; es: electrostatic force; Int_en: intramolecular energy.

Table 2 Binding free energy of $\beta-\mathrm{CD} / 0-\mathrm{NP}$ and $\beta-\mathrm{CD} / p-\mathrm{NP}$ complexes $^{a}$

\begin{tabular}{llllllll}
\hline Host & Guest & Pose & $\Delta G_{\text {vdw }}\left(\mathrm{kcal} \mathrm{mol}^{-1}\right)$ & $\Delta G_{\text {ele }}\left(\mathrm{kcal} \mathrm{mol}^{-1}\right)$ & $\Delta G_{\text {pol }}\left(\mathrm{kcal} \mathrm{mol}^{-1}\right)$ & $\Delta G_{\text {apol }}\left(\mathrm{kcal} \mathrm{mol}^{-1}\right)$ & $\Delta G_{\text {bind }}\left(\mathrm{kcal} \mathrm{mol}^{-1}\right)$ \\
\hline$\beta$-CD & $o$-NP & 1 & -20.5390 & -2.5308 & 7.6752 & -2.1990 & -17.5936 \\
& & 2 & -18.9611 & -3.8562 & 8.5227 & -2.2438 & -16.5384 \\
& & 3 & -20.7589 & -0.7602 & 6.5749 & -2.1896 & -17.1338 \\
& $p$-NP & 1 & -19.9659 & -2.0028 & 7.7360 & -2.3458 & -16.5785
\end{tabular}

${ }^{a} \Delta G_{\mathrm{vdw}}$ : van der Waals contribution; $\Delta G_{\text {ele }}$ : electrostatic contribution; $\Delta G_{\text {pol}}$ : polar solvation contribution; $\Delta G_{\text {apol }}:$ nonpolar solvation contribution; $\Delta G_{\text {bind }}$ : binding free energy; $\Delta G_{\text {bind }}=\Delta G_{\mathrm{vdw}}+\Delta G_{\text {ele }}+\Delta G_{\text {pol }}+\Delta G_{\text {apol }}$.

be a dynamic equilibrium process between $\beta-\mathrm{CD}$ and NP molecules. ${ }^{21}$ In this sense, $\mathrm{NO}_{2}$ group of $\mathrm{NP}$ molecule could reach the surface of the electrode.

\subsection{Selectivity, reproducibility, and stability}

To testify the selectivity of the proposed electrochemical sensor, the reduction currents of $10 \mu \mathrm{M} o$-NP and $p$-NP on the Au@CSiC$\mathrm{SH} / \mathrm{NH}_{2}-\mathrm{CD} / \mathrm{GCE}$ were compared with signals obtained in the absence and presence of 20 -fold concentrations of the interfering species (phenol, paracetamol, catechol, hydroquinone, 2,4-dinitrophenol, glucose, and citric acid). The results that the presence of the above mentioned common interferents in the system did not affect the reduction currents responses of $o$-NP and $p$-NP (Fig. 5D). In addition, no significant interference from some common ions (e.g. $\mathrm{Ca}^{2+}, \mathrm{Mg}^{2+}, \mathrm{Zn}^{2+}, \mathrm{Al}^{3+}, \mathrm{Fe}^{3+}, \mathrm{SO}_{4}{ }^{2-}$ and $\mathrm{NO}_{3}{ }^{-}$) was observed even with 500-fold excess of concentrations of NP isomers. The high selectivity of this method would be beneficial for the detection of $o$-NP and $p$-NP in actual water sample.

The reduction peak currents of $1 \mathrm{mM}$ of $o$-NP and $p$-NP were measured by 6 equal Au@CSiC-SH/ $\mathrm{NH}_{2}-\mathrm{CD} / \mathrm{GCE}$ in $0.1 \mathrm{M}$ PBS (pH 6.0) in parallel, and then were compared to evaluate the fabrication reproducibility of the Au@CSiC-SH/NH$-\mathrm{CD}$ modified electrode. The 6 as-modified electrodes exhibited similar electrochemical responses that the relative standard deviation (RSD) of the current response values were $3.5 \%$ and $2.9 \%$ for $o$ NP and $p$-NP (data not shown), respectively, indicating satisfactory reproducibility.

Successive cyclic potential scans for 50 cycles and long-term storage assays were used to examine the stability of the $\mathrm{Au} @ \mathrm{CSiC}-\mathrm{SH} / \mathrm{NH}_{2}-\mathrm{CD}$ modified electrode. The as-constructed sensor show $97.5 \%$ and $96.8 \%$ of the initial peak current of $1 \mathrm{mM} o$-NP and $p$-NP, respectively, after 30 continuous cycle scans. Additionally, a long-term stability experiment was performed intermittently (every $5 \mathrm{~d}$ ). The constructed sensor was stored in a refrigerator at $4{ }^{\circ} \mathrm{C}$ until use. A $97.5 \%$ of initial current responses was remained after storage for $7 \mathrm{~d}$, revealing an acceptable stability of the $\mathrm{Au}$ (a) $\mathrm{CSiC}-\mathrm{SH} / \mathrm{NH}_{2}-\mathrm{CD}$ modified electrode.

Table 4 shows that the Au@CSiC-SH/ $\mathrm{NH}_{2}-\mathrm{CD} / \mathrm{GCE}$ exhibits a lower detection limit and a wider linear range of NP isomers than the other electrodes. Thus, the fabricated electrode could be used to simultaneously detect $o$-NP and $p$-NP in aqueous solutions with high sensitivity. The excellent detection performance of the sensor may be attributed to the following reasons: (1) the higher supramolecular recognition and enrichment capability of $\beta$-CD host molecules ( $\mathrm{SH}-\beta-\mathrm{CD}$ and $\mathrm{NH}_{2}-\mathrm{CD}$ ) of the $\mathrm{Au} @ \mathrm{CSiC}-\mathrm{SH} / \mathrm{NH}_{2}-\mathrm{CD}$ nanocomposite; (2) the high surface area, the excellent conductivity, the excellent catalytic activity of CSiC for NP isomers reduction; (3) the outstanding conductivity properties of fairly well loaded Au NPs.

\subsection{Real sample analysis}

The proposed method was used to detect $o$-NP and $p$-NP in tapwater and wastewater samples using standard addition methods to evaluate the feasibility of the Au@CSiC-SH/NH$-\mathrm{CD} /$ GCE for real sample analysis. The results showed recoveries ranging from $98.0 \%$ to $102 \%$ with RSDs ranging from $2.5 \%$ to $3.2 \%$ (Table 3), suggested that the constructed chemical sensor

Table 3 Determination of $o-N P$ and $p$-NP in tap-water $(n=3)$

\begin{tabular}{|c|c|c|c|c|c|c|c|c|}
\hline \multirow[b]{2}{*}{ Sample } & \multicolumn{2}{|c|}{ Added $(\mu \mathrm{M})$} & \multicolumn{2}{|c|}{$\begin{array}{l}\text { Founded } \\
(\mu \mathrm{M})\end{array}$} & \multicolumn{2}{|c|}{ RSD (\%) } & \multicolumn{2}{|c|}{ Recovery (\%) } \\
\hline & $o$-NP & $\mathrm{p}-\mathrm{NP}$ & $o$-NP & $\mathrm{p}-\mathrm{NP}$ & $o-\mathrm{NP}$ & $\mathrm{p}-\mathrm{NP}$ & $o-\mathrm{NP}$ & $\mathrm{p}-\mathrm{NP}$ \\
\hline 1 & 1 & 1 & 0.98 & 1.02 & 2.8 & 3.0 & 98.0 & 102.0 \\
\hline 2 & 5 & 5 & 5.05 & 4.98 & 3.1 & 2.5 & 101.0 & 99.6 \\
\hline 3 & 10 & 10 & 10.08 & 10.12 & 2.7 & 3.2 & 100.8 & 101.2 \\
\hline
\end{tabular}


Table 4 Comparison of the proposed electrochemical sensor for detection of o-NP and $p$-NP with others

\begin{tabular}{|c|c|c|c|c|c|}
\hline Sample & Electrode & Method & $\begin{array}{l}\text { Linear range } \\
(\mu \mathrm{M})\end{array}$ & LOD $(\mu \mathrm{M})$ & Ref. \\
\hline \multirow[t]{4}{*}{$o$-NP } & Gr-Chit/ABPE & LSV & $0.4-80$ & 0.20 & 26 \\
\hline & CD-RGO/GCE & DPV & $7.2-64.7$ & 0.14 & 11 \\
\hline & $\mathrm{Fe}_{3} \mathrm{O}_{4}-\mathrm{Pt} / \mathrm{GCE}$ & DPV & $0.1-1.5$ & 0.069 & 28 \\
\hline & CD-SBA/CPE & DPV & $0.2-1.4$ & 0.01 & 22 \\
\hline \multirow[t]{6}{*}{$p$-NP } & S-CHIT/ABPE & LSV & $0.08-2$ & 0.03 & 30 \\
\hline & $\mathrm{GO} / \mathrm{GCE}$ & LSV & $0.1-120$ & 0.02 & 1 \\
\hline & $\mathrm{nAg}$-chitosan/GCE & SWV & $0.07-2$ & 0.07 & 31 \\
\hline & OMCs/GCE & DPV & $2-90$ & 0.1 & 29 \\
\hline & Nano-gold/GCE & DPV & $10-1000$ & 8 & 32 \\
\hline & Bridged- $\beta$-CD-MWCNT/GCE & DPV & $0.1-200$ & 0.048 & 33 \\
\hline
\end{tabular}

based on $\mathrm{Au} @ \mathrm{CSiC}-\mathrm{SH} / \mathrm{NH}_{2}-\mathrm{CD}$ nanocomposite has the practical application. These results suggested that Au@CSiC-SH/ $\mathrm{NH}_{2}$-CD nanocomposite modified electrode may be a better choice for the electrochemical sensing of $o$-NP and $p$-NP.

\section{Conclusions}

In summary, in this work, $\mathrm{SH}-\beta-\mathrm{CD}$ and $\mathrm{NH}_{2}-\mathrm{CD}$ were simultaneously connected to $\mathrm{Au} @ \mathrm{CSiC}$ by $\mathrm{Au}-\mathrm{S}$ bond and amide bond to prepare composite modified electrode. The electrochemical sensor was successfully used for simultaneous detection of $o$-NP and $p$-NP by DPV upon optimal experimental conditions. Due to the good electron transfer property of $\mathrm{CSiC}$ and the excellent molecular recognition capability of SH- $\beta$-CD and $\mathrm{NH}_{2}-\mathrm{CD}$, the developed Au@CSiC-SHCD/ $\mathrm{NH}_{2}-\mathrm{CD} / \mathrm{GCE}$ displays excellent analytical performance for the electrochemical sensing of $o$-NP and $p$-NP: the linear range of $o$-NP was between $0.01-5.00$ and 5$150 \mu \mathrm{M}$, the detection limit was $0.019 \mu \mathrm{M}(\mathrm{S} / \mathrm{N}=3)$, and the linear range of $p$-NP was in the range of $0.01-5.00$ and 5-150 $\mu \mathrm{M}$, the detection limit is $0.023 \mu \mathrm{M}(\mathrm{S} / \mathrm{N}=3)$. The experimental results show that the sensor has good reproducibility, stability and selectivity, which can be used for the actual water sample detection. The recoveries are between $98.0-102.0 \%$ and the results are satisfactory.

In addition, in this experiment we propose the introduction of two single modified $\beta$-CDs at the same interface of sensing plat, which enhances the molecular recognition ability of $o$-NP and $p$-NP and provides a promising electrochemical sensing platform for the simultaneous analysis of multianalytes at an identical interface. The experiment is simple, rapid and sensitive. The sensor is expected to be used in selective inspection environments pollutants, with a certain practical value.

\section{Conflicts of interest}

There are no conflicts to declare.

\section{Acknowledgements}

This work was financially supported by the National Natural Science Foundation of China $(21764005,21565029)$ and the Program for Donglu Scholars, Yunnan University.

\section{References}

1 J. Li, D. Kuang, Y. Feng, F. Zhang, Z. Xu and M. Liu, J. Hazard. Mater., 2012, 201-202, 250-259.

2 W. Zhang, J. Chang, J. Chen, F. Xu, F. Wang, K. Jiang and Z. Gao, Res. Chem. Intermed., 2012, 38, 2443-2455.

3 D. M. Whitacre, Reviews of environmental contamination and toxicology, Springer, New York, 2010.

4 G. Thouand, P. Friant, F. Bois, A. Cartier, A. Maul and J. C. Block, Ecotoxicol. Environ. Saf., 1995, 30, 274-282.

5 G. Thouand, B. Captdevielle and J. C. Block, Ecotoxicol. Environ. Saf., 1996, 33, 261-267.

6 M. R. H. Podeh, S. K. Bhattacharya and M. Qu, Water Res., 1995, 29, 391-399.

7 G. Schüürmann, R. K. Somashekar and U. Kristen, Environ. Toxicol. Chem., 1996, 15, 1702-1708.

8 N. C. Saha, F. Bhunia and A. Kaviraj, Bull. Environ. Contam. Toxicol., 1999, 63, 195-202.

9 R. P. Pohanish, Sittig's Handbook of toxic and hazardous chemicals and carcinogens, William Andrew, Oxford, 2008.

10 Z. Liu, J. Du, C. Qiu, L. Huang, H. Ma, D. Shen and Y. Ding, Electrochem. Commun., 2009, 11, 1365-1368.

11 Z. Liu, X. Ma, H. Zhang, W. Lu, H. Ma and S. Hou, Electroanalysis, 2012, 24, 1178-1185.

12 US Environmental Protection Agency, Fed. Regist., 1989, 52, 131.

13 K. Asadpour-Zeynali and P. Najafi-Marandi, Electroanalysis, 2011, 23, 2241-2247.

14 M. Megharaj, H. W. Pearson and K. Venkateswarlu, Arch. Environ. Contam. Toxicol., 1991, 21, 578-584.

15 V. Uberoi and S. K. Bhattacharya, Water Environ. Res., 1997, 69, 146-156. 
16 Y. Wei, L. T. Kong, R. Yang, L. Wang, J. H. Liu and X. J. Huang, Langmuir, 2011, 27, 10295-10301.

17 G. Zhu, Y. Yi and J. Chen, TrAC, Trends Anal. Chem., 2016, 80, 232-241.

18 H. Zhao, L. Yang, Y. Li, X. Ran, H. Ye, G. Zhao, Y. Zhang, F. Liu and C. P. Li, Biosens. Bioelectron., 2017, 89, 361-369.

19 Z. Zhang, S. Gu, Y. Ding, M. Shen and L. Jiang, Biosens. Bioelectron., 2014, 57, 239-244.

20 G. Zhu, X. Zhang, P. Gai, P. Gao, X. Zhang and J. Chen, Nanoscale, 2012, 4, 5703-5709.

21 Y. Guo, S. Guo, J. Ren, Y. Zhai, S. Dong and E. Wang, ACS Nano, 2010, 4, 4001-4010.

22 X. Xu, Z. Liu, X. Zhang, S. Duan, S. Xu and C. Zhou, Electrochim. Acta, 2011, 58, 142-149.

23 L. Yang, H. Zhao, S. Fan, B. Li and C. P. Li, Anal. Chim. Acta, 2014, 852, 28-36.

24 W. C. Wu, H. W. Chang and Y. C. Tsai, Chem. Commun., 2011, 47, 6458-6460.
25 A. Oliveros, A. Guiseppi-Elie and S. E. Saddow, Biomed. Microdevices, 2013, 15, 353-368.

26 P. Deng, Z. Xu and J. Li, Microchim. Acta, 2014, 181, 10771084.

27 L. Luo, X. Zou, Y. Ding and Q. Wu, Sens. Actuators, B, 2008, 135, 61-65.

28 G. G. Gerent and A. Spinelli, J. Hazard. Mater., 2017, 330, 105-115.

29 T. Zhang, Q. Lang, D. Yang, L. Li, L. Zeng, C. Zheng, T. Li, M. Wei and A. Liu, Electrochim. Acta, 2013, 106, 127-134.

30 P. Deng, Z. Xu, Y. Feng and J. Li, Sens. Actuators, B, 2012, 168, 381-389.

31 C. A. de Lima, P. S. D. Silva and A. Spinelli, Sens. Actuators, B, 2014, 196, 39-45.

32 L. Chu, L. Han and X. Zhang, J. Appl. Electrochem., 2011, 41, 687-694.

33 L. Yang, S. Fan, G. Deng, Y. Li, X. Ran, H. Zhao and C. P. Li, Biosens. Bioelectron., 2015, 68, 617-625. 